\title{
3D Simulation of fatty acid methyl ester production in a packed membrane reactor
}

\author{
Baharak Sajjadi, Abdul Aziz Abdul Raman, Saeid Baroutian, \\ Shaliza Ibrahim, Raja Shazrin Shah Raja Ehsan Shah
}

Introduction

The necessity to replace conventional fossil fuels with an environmental friendly substitute to fulfil the increasing energy demand has been a great concern in this century [1,2]. Reserves have been cited to last only for another 50 years at the current consumption rate of crude oil [3]. Biodiesel (fatty acid alkyl esters) is one of the most promising alternative fuels. It is now recognised as "green fuel" and brings several advantages over conventional fossil fuels. It is biodegradable, renewable, non-toxic and has very similar properties to diesel fuel [4]. Biodiesel is the only alternative fuel that can be used directly in any existing, unmodified diesel engine as it has similar properties to petroleum diesel. Furthermore biodiesel can be blended in any ratio with petroleum diesel [5-7]. Biodiesel can be produced using homogeneous, heterogeneous or biocatalysts. Generally, transesterification of triglycerides using homogeneous catalysts is the most preferable processing technique. This method contains three steps to exchange the alkoxy group of an alcohol with the alkoxy group of an ester compound.

However, this technique suffers from high cost for purification and wastewater treatment [8]. Although enzymatic catalysts give high conversion rate and are very selective, they are unstable and very expensive [9]. Heterogeneous acid-catalysed process is an advantageous alternative method that can overcome the above challenges.

The main difficulty in biodiesel production is the immiscible nature of the reactants and the difference in their densities. This can result in poor contact between the reactants thereby reducing mass transfer and reaction rate and also direct increase in the reaction time

Transport of mass, heat and fluid between two immiscible fluids is similar to heterogeneous transport phenomena and depends on the lag in the film between them. Changing fluid physical properties or increasing the driving force could raise the transport rates. The best way to overcome the lag is the film mixing membrane reactor which is one of the techniques employed to overcome process challenges and produce high quality biodiesel [10].

Besides this, themethod can overcome the usual technical problems such as higher energy consumption of continuous stirred tank reactors (CSTR), high alcohol usage, high reaction temperature as well as high time demand to obtain complete conversion. In fact, the membrane is used in both the reaction bed and separator and then it provides high surface/volume ratio for mass transfer and separation. This method is easy to scale up [11].

Based on the membrane material, the membrane can be classified into organic, inorganic, dense or porous membrane. [12]. The inorganic membranes especially ceramic ones are able to endure higher pressure and temperature; thus they are more suitable for use with organic solvents in comparison with the organic or porous types. The other classification means the membrane is either able to incorporate with the catalyst or not. That is to say, it is known as a catalytic or inert membrane reactor. In the inert type, catalysts are charged to the reactants. The most widely used inert membranes in biodiesel production are the 
ceramic membrane [13], carbon membrane [14] and the $\mathrm{TiO}_{2} / \mathrm{Al}_{2} \mathrm{O}_{3}$ in ceramic membrane [15].

Furthermore, potassium hydroxide, sodium hydroxide and sulphuric acid are the most common catalysts used for catalytically inert membranes [13-16.

In this research, a packed bed membrane reactor containing heterogeneous catalyst was used with the aim of combining alkali transesterification and triglyceride separation. For this purpose a tubular ceramic $\left(\mathrm{TiO}_{2} / \mathrm{Al}_{2} \mathrm{O}_{3}\right)$ membrane was employed as both a reactor and a separator and it is filled with potassium hydroxide catalyst supported on activated carbon.

Understanding the microscopic fluid flow in a membrane module based on CFD analysis can improve the design of the collection of tubes and spacers to enhance module performance and facilitate the construction of new designs; then CFD techniques were applied to solve the model equations. A three-dimensional numerical solution of the coupled Navier-Stokes, Brinkman's lawand chemical reaction equations has been developed using the control volume based finite difference method. The main objective of the simulation is to predict concentrations of the components in the membrane contactor. Moreover, the laminar fluid flow and chemical reaction through the catalytic bed and the component concentrations inside the ceramic membrane have been investigated. Finally, the model predicted results were validated with experimental data.

\section{Experimental data}

The experimental data was taken from the work of Baroutian et al. and consisted of two different temperatures and two different fluid cross flow velocities [17,27]. Fig. 1 shows the laboratory scale experimental setup for FAME production. A tubular $\mathrm{TiO}_{2} / \mathrm{Al}_{2} \mathrm{O}_{3}$ membrane (Atech Innovations Gmbh, Germany) with $0.05 \mu \mathrm{m}$ nominal pore size was used as reactor and separator (Fig. 2). The length, inner diameter and outer diameter of the membrane were $40 \mathrm{~cm}, 1.60 \mathrm{~cm}$ and $2.54 \mathrm{~cm}$, respectively. The effective filtration area for the membrane was $0.0201 \mathrm{~m} 2$. The inner section was packed with potassium hydroxide catalyst supported on palm shell activated carbon. It loaded the membrane with 50 vol. \% of the catalyst, which was considered as the catalytic bed porosity. Beside these, they were kept in a place using stainless steel screens attached to the upstream and downstream tubing; then uniform distribution of the catalyst has been assumed in the CFD section. The characterisation result of the catalytic bed has been shown in Table 1. A coiled heat exchanger equipped with a hot water circulator bath was used to maintain the reaction temperature. The system pressure (transmembrane pressure, TMP) was maintained throughout the run andwas controlled at 1 barg. Palmoil andmethanol with the volume ratio of $1: 1$ were charged into the system. Palmoil had with molecular weight of $762.223(\mathrm{gr} / \mathrm{mol})$ density of $870.2(\mathrm{~kg} / \mathrm{m} 3)$ and viscosity of $16.93(\mathrm{mPa} \cdot \mathrm{s})$. The other properties of palmoil include an acid value of 0.5 , iodine value of 53.2 and water mass fraction of $400 \times 10-6$. Methanolwith amolecularweight of $32.04(\mathrm{~g} / \mathrm{mol})$, purity of $99.8 \%$, density of $791.8(\mathrm{~kg} / \mathrm{m} 3)$ and viscosity of $0.59(\mathrm{mPa} \cdot \mathrm{s})$ is the other reactant. Finally, potassium hydroxide loaded on activated carbon was used as the heterogeneous catalyst within the catalytic bed.

In this study, selection of level for each parameter was based on the literature reports on the applications of alkali transesterification reactions. The lower and upper levels of temperature $\left(50\right.$ and $\left.60{ }^{\circ} \mathrm{C}\right)$ respectively were due to the very slow rate of the reaction in the temperature less than $50{ }^{\circ} \mathrm{C}$ and the boiling point of methanol at the upper level. The levels of cross flow circulation velocity were selected due to the capability of the circulating pump. The catalyst concentration was also based on the design matrix. Finally, selection of methanol to palm 
oil ratio was due to the mixing limitation of ceramic membrane. Since

in this technology, there is no effectivemixingwithin the ceramicmembrane,

the other mass transfer limitation such as the immiscible nature

of the reactantswill join the process. Therefore themethanol concentration

should be more than what is normally used in the other methods.

According to literature, the alcohol concentration of 40:1 43:1 is sufficient

in membrane technology in the presence of heterogeneous catalyst

[18]. In this study the alcohol to methanol ratio of 1:1 (vol.\%) was

used which is less than 24:1 molar ratio.

Triglyceride (TG) was not miscible inMeOH, it was found in form of

small droplets during the transesterification reaction. Therefore, the produced biodiesel which consists of fatty acid alkyl esters with small molecular sizes was able to pass through the membrane along with alcohol

and glycerolwhile the large droplet of oil cannot pass through the

membrane pores. Therefore, in the CFD simulation, it was considered

that all components can pass through the membrane except the TG

due to its droplet size [19-25]. Generally, the membrane technology is

a newand complicated knowledge especially in biodiesel field. Furthermore,

there are still, so many unknowns in this area. In this study, we

tried to find out some of these unknowns such as local component concentration

within the ceramic membrane and catalytic bed at different

times with the assistance of CFD simulation. 30 different experiments

were designed and optimised. According to the available kinetic information

with the literature the mentioned two runs were selected for

the simulation [26]. Table 2 shows all the reaction rate constants, $\mathrm{k}$

(wt.\% $\mathrm{min}$ )- 1 in two different temperatures.

Full text is available at :

http://www.sciencedirect.com/science/article/pii/S0378382013002555 